Rev. Saude pübl, S. Paulo

15:263-71, 1981

\title{
OCORRENCIA DE SILICOSE ENTRE TRABALHADORES DA INDÚSTRIA CERÂMICA DA CIDADE DE JUNDIAI, SP (BRASIL)
}

Diogo Pupo Nogueira*

$\dagger$ Diógenes Certain**

Roberto Brólio**

Nelson M. Garrafa **

Harry Shibata***

\begin{abstract}
NOGUEIRA, D.P. et al. Ocorrência de siltcose entre trabalhadores da indústria cerâmica da cidade de Jundiaf, SP (Brasil). Kev. Saúde públ., S. Paulo, 15:263-71, 1981.

RESUMO: Tomando-se conio ponto de partida a descoberta de um caso de silicose entre trabalhadores da indústria cerâmica, que tradicionalmente era considerada como pouco importante na gênese dessa pneumoconiose, foi possivel, através de exame radiológico, evidenciar que uma proporção muito elevada dos trabalhadores desse tipo de indústria é portadora de alteraçóes radiológicas características da silicose. Descrevem-se os achados radiológicos, que na sua maioria foram de opacidades regulares de pequeno tamanho. Com base nesse trabalho foi possivel fazer-se a descoberta de outros "focos" de silicose em outras áreas do Estado de São Paulo.
\end{abstract}

UNITFRMOS: Silicose, Jundiaí, SP, Brasil. Doenças profissionais.

\section{INTRODUÇAO}

Poucas doenças profissionais revelam a enorme importância da epidemiologia em estudos de Saúde Ocupacional como a silicose.

Conforme descreve Hunter 5 , já em 1556 o médico alemão Georg Bauer, mais conhecido pelo seu nome latino de Georgius Agricola, tinha descrito no seu livro "De Re Metallica" o fato de que os mineiros que trabalhavam em minas de ouro e de prata na região de Joachimstahl apresentavam alta mortalidade causada por uma doença pulmonar por eles chamada de "tísica dos mineiros" que, indiscutivelmente, eram casos de silicose.

No entanto, essa primeira descrição da silicose permaneceu ignorada praticamente até os nossos dias. Através de estudos de casos individuais, sabia-se que os mineradores de determinados tipos de rochas apresentavam doença pulmonar que recebia os mais diversos nomes tais como "doença dos ceramistas", "doença dos esmerilhadores", entre outros; não havia, no entanto,

* Do Departamento de Saúde Ambiental da Faculdade de Saúde Pública da USP - Av. Dr. Arnaldo, 715 - 01255 - São Paulo, SP - Brasil.

* Do Departamento de Epidemiologia da Faculdade de Saúde Pública da USP - Av. Dr. Arnaldo, 715 - 01255 - São Paulo, SP - Brasil.

*** Do Instituto Médico Legal do Estado de São, Paulo - Rua Teodoro Sampaio, $151-05405$ - São Paulo, SP - Brasil. 
NOGUEIRA, D.P. et al. Ocorréncia de silicose entre trabalhadores da indústría ceramica da cldade de Jundial, SP (Brasil), Rev, saude puibl., S. Paulo, 15:263-71, 1981.

nenhuma idéia estabelecida quanto ao agente etiológico que provocava tais doenças.

Como bem o afirma Densen ${ }^{2}$, a razão do desconhecimento quanto à etiologia dessas aparentemente diversas doenças residia no fato de que "... a atenção estava fixada quase que exclusivamente em casos individuais de silicose. Não existia nenhuma tentativa de relacionar os casos ao número total de pessoas expostas ao risco, pelo que não era possivel se medir a magnitude desse problema de saúde, em particular. Sem alguma medida das dimensões do problema, era impossivel verificar-se se essas dimensões variavam em diferentes ocupações e, se isso acontecia, se tal variaçăo guardava qualquer relaçăo às condições de exposição".

Deve-se a Collis 1, através das suas famosas "Milroy Lectures" em 1915, levar ao conhecimento da relação entre a doença pulmonar dos mineiros e o dióxido de silicio, $\mathrm{SiO}_{2}$.

Os estudos de Collis 1 basearam-se fundamentalmente em atestados de óbitos, levando em consideração não somente os trabalhadores expostos a poeiras, mas também a população não exposta.

Collis 1 estabeleceu o risco de morte em diversas profissões, notando a mortalidade maior dos mineiros. Estudando o tipo de poeira a que estes estavam expostos, verificou que a mortalidade era maior quando havia exposição ao dióxido de silício. Assim, assinalava ele que ". o estudo da prevalência da tísica em ocupações onde há exposição a poeiras demonstrou não existir correlação definida entre a quantidade de poeira presente e a prevalência da doença" mas que ". outras evidências demonstraram que, sempre que a tísica está presente, um tipo especial de poeira também está presente, a saber: poeira de sílica cristalina". Assim, assinalava ele, ". . a a afirmativa de que não existe relação definida entre a quantidade de poeira presente e a prevalência da tísica não é verdadeira se a presença de sílica for considerada, pois há evidência de que a prevalência da doença ceteris paribus varia diretamente com a quantidade de sílica presente".

Não satisfeito em demonstrar que apenas os mineiros expostos à sílica livre adquiriam a doença, Collis 1 ainda estudou a mortalidade das mulheres de mineiros, para verificar se fatores locais - clima, hábitos entre outros - não poderiam explicar a doença. Como a mortalidade dessas mulheres era semelhante à da população geral, ficou claramente evidenciado o fato de que a maior mortalidade dos mineiros era decorrência da exposição a poeiras contendo silica livre.

Portanto, não obstante terem decorrido 359 anos desde a primeira descrição da doença por Agricola, somente em 1915 ficou mostrado, através de um estudo epidemiológico baseado em atestado de óbito, que a mesma era devida ao dióxido de silicio exclusivamente.

Como bem o mostra Mendes e col..7, na sua excelente revisão histórico-bibliográfica da literatura cientifica brasileira sobre pneumoconioses, os estudos epidemiológicos sobre silicose são rèlativamente escassos no nosso mejo. Os primeiros estudos sobre o assunto baseavam-se fundamentalmente em casos individuais e somente a partir de 1936-1937 iniciaram-se estudos de natureza realmente epidemiológicos, onde a relação agente-meio-hospedeiro passava a ser considerada. No entanto, como diz Mendes e col. ${ }^{7}$ tais estudos ". por serem realizados em amostras, não servem para identificar estabelecimentos, nem para avaliar a proporção de "expostos"/ "doentes", tão importante na silicose, onde entram em jogo variáveis como "tempo de exposição", "concentração e tamanho das partículas", "teor de sílica nas poeiras", e muitas outras. Por sua vez, inquéritos de morbidade (geral ou especificos para a silicose, no caso) são, da mesma forma, extremamente onerosos, dependem da concordância dos estabelecimentos industriais e necessitam de semiologia radiológica para terem significado no 
NOGUEIRA, D.P. et al. Ocorrência de silicose entre trabalhadores da indústria ceramica da cidade de Jundiaí, SP (Brasil). Rev. Saúde pübl., S. Paulo, 15:263-71, 1981.

caso da silicose, o que, naturalmente, mobilizaria recursos extremamente elevados".

O objetivo do presente trabalho é o de descrever uma "epidemia" de silicose ocorrida recentemente no Estado de São Paulo, que permitiu a identificação de uma atividade laborativa como sendo de alto risco no desenvolvimento dessa grave pneumoconiose.

O trabalho com cerâmica, particularmente com cerâmica sanitária, era até há pouco tempo atrás considerado como sendo de importância relativa na gênese da silicose. Assim, Mendes e col. ${ }^{7}$, atualizando para o periodo de 1947 a 1978 o trabalho feito por Minervino e col. ${ }^{8}$ na Subdivisão de Recenseamente Torácico do SESI, verificou que em 556 casos de silicose, apenas 42 $(7,5 \%)$ ocorriam em trabalhadores que procediam à operação de polimento de louças. O próprio Mendes e col.7, na sua cuidadosa observação de 119 casos de silico-tuberculose, encontrou apenas $8(6,7 \%)$ procedentes da indústria de cerâmicas e louças. Portanto, os escassos levantamentos brasileiros evidenciavam que o trabalho de manufatura de louça sanitária não constituia, aparentemente, risco importante na gênese da silicose.

Em 1973, um dos autores (H.S.), tendo sido nomeado perito da Justiça do Trabalho em um caso de reclamação de indenização por silicose, teve a ocasião de estudar em detalhe o local de trabalho do reciamante, que era uma indústria de cerâmica sanitária da cidade de Jundiaí, Estado de São Paulo. A observação acurada das condições em que o trabalho era realizado veio mostrar a possível existência de riscos para a ocorrência da silicose.

$\mathrm{Na}$ fabricação da cerâmica sanitária, utilizam-se principalmente 0 caulim, o quartzo, o feldspato e a argila. Segundo Evans ${ }^{3}$, dependendo do produto que será elaborado, o teor de quartzo na mistura pode atingir até $35 \%$; a isso se acresce o fato de que a argila, que contém até $50 \%$ de silica livre, pode ser utilizada em proporção de até $50 \%$, com o que o produto final (massa) pode conter até $50 \%$ de sílica livre.

A operação chamada de "fundição" é a que expõe os trabalhadores a maior quantidade de poeira. Os moldes para os diversos aparelhos sanitários - lavatórios, pias, bacias de privada entre outros, feitos de gesso são inicialmente molhados e, a seguir, empoados com talco, que evita a aderência da massa ao molde. A massa, composta dos produtos acima mencionados em mistura com água, é lançada dentro dos moldes e deixada secar em ambiente cuja temperatura é artificialmente elevada. Uma vez seca a peça, esta é retirada do molde, procedendo-se ao chamado "acabamento a verde": com uma faca e uma lixa, o trabalhador procura retirar as rebarbas existentes, com o objetivo de dar à peça uma superfície perfeitamente lisa e uniforme: durante essa operação desprende-se grande quantidade de poeira, que é dispersada no ar não só pela movimentação dos trabalhadores como pelos ventiladores que existem no local com o objetivo de facilitar a secagem. Terminada essa operação, as peças são enviadas para a seção de esmaltação, onde o esmalte é aplicado por atomização; segue-se a queima das peças em fornos-túneis, durante 12 a $17 \mathrm{~h}$, a uma temperatura de $1.200^{\circ} \mathrm{C}$, com o que fica terminado o processo de fabricação.

A observação de que o processo de fundição implicava, necessariamente, a produção de poeira que continha elevado teor de sílica livre, e o fato de inexistirem métodos de proteção coletiva ou equipamentos de proteção individual levou aquele autor a suspeitar de que existiam, nas cerâmicas que fabricavam louça sanitária, condições favoráveis ao aparecimento da silicose. Tal suspeita era tanto maior quanto se sabia que, em 1971, a agência do Instituto Nacional de Assistência Médica e Previdência Social (INAMPS) em Amparo tinha diagnosticado um caso de silicose em trabalhador em uma 
NOGUEIRA, D.P. et al. Ocorrência de silicose entre trabalhađores da indústria cerâmica da cidade de Jundiaí, SP (Brasil). Rev. Saúde pübl., S. Paulo, 15:263-71, 1981.

indústria cerâmica da cidade de Amparo (Morrone ${ }^{9}$ ). Em face disso foi decidido ser levado a cabo um estudo radiológico sobre a possibilidade da ocorrência da silicose na indústria de cerâmica sanitária da cidade de Jundiai e de algumas outras cidades vizinhas.

A perícia judicial referida levou o sindicato dos trabalhadores a se interessar pelo problema e com o seu auxílio foi possivel ser efetivado tal estudo sendo o mesmo realizado no período de maio de 1973 a outubro de 1975.

\section{MATERIAL E MÉTODOS}

O exame radiológico foi realizado na própria cidade de Jundiai, por intermédio do sindicato dos trabalhadores cerâmicos local que enviou para exame, 85 radiografias de trabalhadores da indústria cerâmica da cidade de Jundiai, do sexo masculino, com idades que variavam de 26 a 60 anos (média: $41,28 \pm 7,09$ )

A leitura das radiografias foi realizada no setor de Tisiologia do Departamento de Epidemiologia da Faculdade de Saúde Pública da Universidade de São Paulo, sendo classificadas de acordo com a Classificação Internacional de Pneumoconioses de 1971, da Organização Internacional do Trabalho ${ }^{~}$.

\section{RESULTADOS E COMENTARIOS}

Dos 85 trabalhadores que foram estudados, 9 deles apresentaram resultado do exame radiológico tecnicamente mau, não permitindo leitura; solicitados a se submeterem novamente ao exame, não o fizeram, pelo que o grupo final, portador de radiografias consideradas como tecnicamente satisfatórias pelos leitores, foi de 76 pessoas.

Como se verifica pela Tabela 1, 20 trabalhadores $(26,32 \%)$ apresentavam exame radiológico normal, enquanto que a maioria delas (56 pessoas - $76,68 \%$ ) apresentavam alterações radiológicas bem definidas, características da pneumoconiose. Trata-se, portanto, de uma proporção extremamente elevada de trabalhadores afetados, mostrando a gravidade da situação.

T A B E L A 1

Achados radiológicos de trabalhadores expostos à poeira de sílica livre, Jundiaí, 1974.

\begin{tabular}{|c|c|c|}
\hline $\begin{array}{l}\text { Sombras } \\
\text { radiológicas * }\end{array}$ & $\mathbf{f}$ & $\%$ \\
\hline 0 & 20 & 26,32 \\
\hline $\mathrm{p}$ & 50 & 65,79 \\
\hline$q$ & 2 & 2,63 \\
\hline $\mathbf{r}$ & 1 & 1,32 \\
\hline $\mathrm{s}$ & 1 & 1,32 \\
\hline$t$ & 2 & 2,62 \\
\hline $\mathrm{u}$ & - & - \\
\hline Total & 76 & 100,00 \\
\hline
\end{tabular}

* Códigos segundo a Classificação Internacional de Pneumoconioses 6 (1971).

Dos 56 trabalhadores que foram radiologicamente considerados como sendo portadores de silicose, a imensa maioria $(89,28 \%)$ era portadora de sombras radiológicas tipo " $p$ " (Tabela 1). De acordo com a Classificação Internacional, as sombras "p" são pequenas opacidades arrendondadas, com diâmetro de cerca de $1,5 \mathrm{~mm}$. A presença de nódulos indica haver formas iniciais da doença.

Opacidades " $q$ " foram observadas em 2 trabalhadores. Tratam-se de nódulos cujo diâmetro se encontra entre $1,5 \mathrm{~mm}$ e 3,00 $\mathrm{mm}$; sua presença indica fase mais progressiva da doença.

Nódulos " $r$ " (diâmetro maior do que 3,0 $\mathrm{mm} e$ inferior a $10 \mathrm{~mm}$ ) indicativos de maior progressão da doença, foram encontrados em apenas um trabalhador.

Além dessas sombras nodulares, em 3 casos foram encontradas pequenas opacidades irregulares. Assim, em um caso 
NOGUEIRA, D.P. et al. Ocorrência de silicose entre trabalhadores da indústria cerâmica da cldade de Jundiai, SP (Brasil). Rev. Saude publ., S. Paulo, 15:263-71, 1981.

foram detectadas imagens "s", que são opacidades finas e lineares, e em dois casos imagens " $t$ ", que são opacidades irregulares de tamanho médio; não foram observadas opacidades " $u$ " (opacidades irregulares de tamanho maior) nem formas $\mathrm{A}, \mathrm{B}$ ou $\mathrm{C}$.

A extensão do processo de fibrose pulmonar causada pela presença do dióxido de silício, nesses trabalhadores, está assinalada na Tabela 2.

De acordo com a Classificação Internacional 6 , as pequenas opacidades estão divididas em quatro categorias, a saber:

Categoria $0-$ pequenas opacidades relativamente raras

Categoria 1 - pequenas opacidades presentes, mas em número reduzido

Categoria 2 - pequenas opacidades numerosas, conjuntamente com alterações da estrutura normal dos pulmōes

Categoria 3 - pequenas opacidades muito numerosas, com a estrutura normal dos pulmões parcial ou totalmente destruida.

No que se refere à opacidade " $p$ ", verifica-se pela Tabela 2 que as mesmas constituiram o principal achado radiológico (50 casos - 89,28\%) apresentando uma extensão pequena em 13 casos $(26 \%$ dos casos "p"). No entanto, em 8 casos (16\% dos casos "p") essas opacidades cobriam todo o parênquima pulmonar.

Nos 2 casos que apresentavam opacidades tipo "q", em um deles o número de nódulos era relativamente pequeno (código $0 / 1$ ) e no outro já área maior era atingida (código $2 / 1)$.

No único caso de sombras tipo " $r$ ", a extensão do processo fibrótico era pequena (código 1/0).

No que respeita às opacidades irregulares, o único caso de sombras tipo "s" já apre- sentava invasão bastante grande da área pulmonar pelo processo fibrótico (código $3 / 3$ ).

Finalmente, nos dois casos de sombras " $t$ ", o processo fibrótico atingia áreas moderadamente restritas do parênquima pulmonar (códigos $1 / 0$ e $1 / 2$ ).

Verifica-se, portanto, que a grande maioria dos trabalhadores da indústria cerâmica e que foram submetidos a exame radiológico dos pulmões apresentavam formas iniciais de fibrose pulmonar, com predominância de nódulos silicóticos de pequeno tamanho que se distribuiu por áreas pouco extensas do parênquima pulmonar. Evidenciava-se, assim, que o trabalho na indústria cerâmica constituia um risco bem definido de adquirir a silicose e que a incidência desta pneumoconiose entre os trabalhadores dessa indústria era muito maior do que se pensava até a época, constituindo, assim, grave problema de Saúde Ocupacional.

A Tabela 3 indica o tempo de exposição à poeira de sílica desse grupo de trabalhadores. Verifica-se que a imensa maioria $(78,56 \%)$ tinha se exposto durante um período de 11 a 25 anos a esse agente de pneumoconiose, sendo de se destacar que 16 casos $(28,56 \%)$ tinham se exposto de 11 a 15 anos. Verifica-se, pois, que houve necessidade, em média, de um período de tempo relativamente longo para que as lesões silicóticas aparecessem.

Note-se, no entanto, que casos de silicose podem aparecer mesmo após exposiçōes relativamente curtas. Assim, em um dos casos, a pneumoconiose foi observada radiologicamente 4 anos após o início da exposição, sendo de se destacar que, inexistindo um exame radiológico anterior para controle, é possivel que opacidades já pudessem ter sido observadas até mesmo mais cedo; por outro lado, nada menos de 4 casos $(7,14 \%)$ apresentavam lesões radiologicamente verificáveis após 6 a 10 anos de exposição, o que bem mostra o erro de 


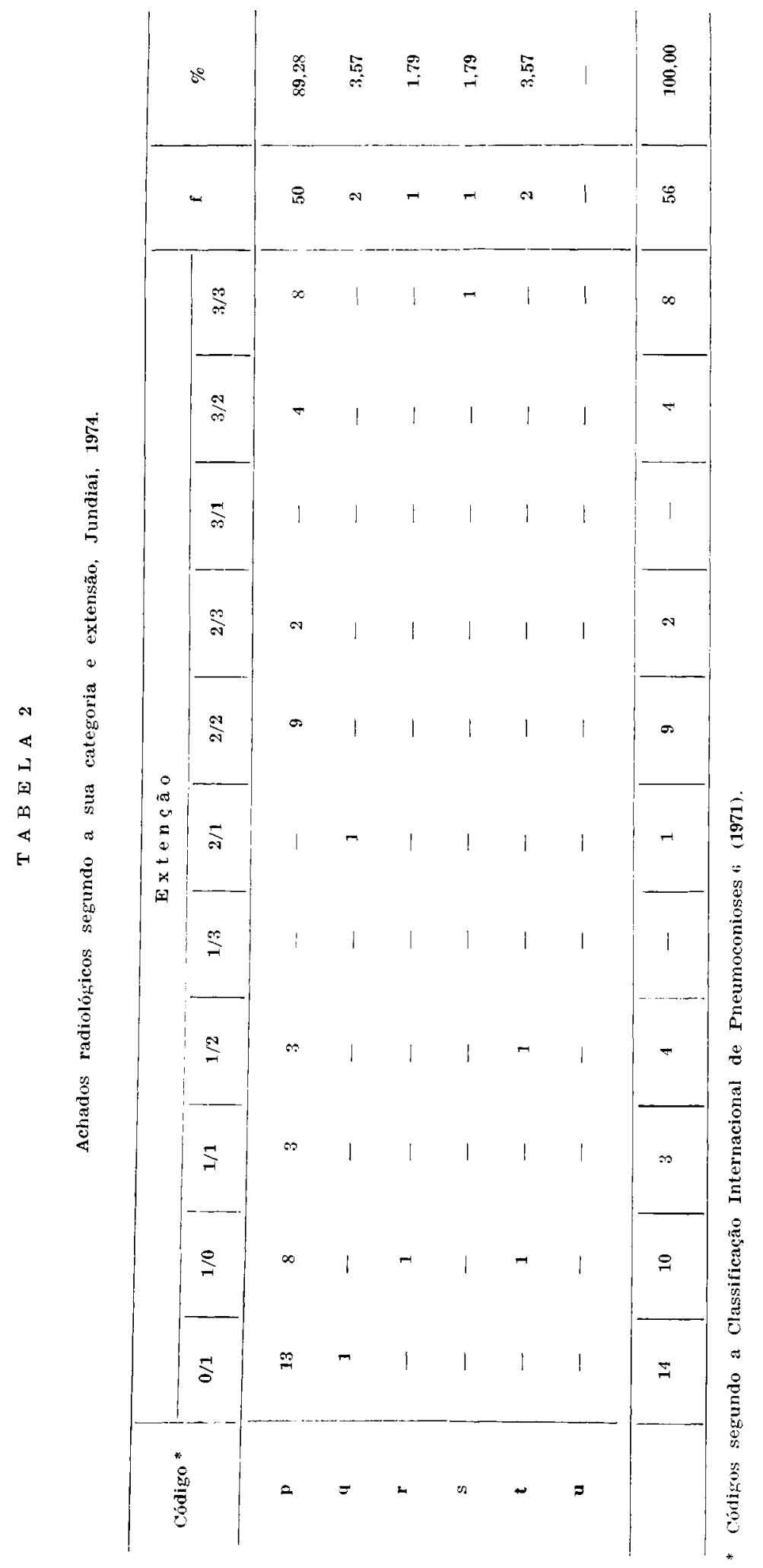


NOGUEIRA, D.P. et al. Ocorrência de silicose entre trabalhadores da indústria ceramica da cidade de Jundial, SP (Brasil). Rev. Sauide públ., S. Paulo, 15:263-71, 1981.

TA B E L A 3

Tempo de exposição à poeira em ceramica, contendo sillca livre dos trabalhadores portadores de alteraçoes radiológicas, Jundiai, 1974.

\begin{tabular}{ccc}
\hline $\begin{array}{c}\text { Tempo de } \\
\text { exposição (anos) }\end{array}$ & 1 & $\%$ \\
\hline até 5 & 1 & 1,79 \\
$6-10$ & 4 & 7,14 \\
$11-15$ & 16 & 28,56 \\
$16-20$ & 14 & 25,00 \\
$21-25$ & 14 & 25,00 \\
$26-30$ & 3 & 5,36 \\
$31-35$ & 3 & 5,36 \\
+ de 35 & 1 & 1,79 \\
\hline Total & 56 & 100,00 \\
\hline
\end{tabular}

antigas afirmações de que a silicose só se manifesta radiologicamente após mais de 10 anos de exposição.

Ainda deve ser notado que nos 20 casos em que o exame radiológico nada mostrou, não se pode afirmar taxativamente que inexiste a pneumoconiose. Realmente, de acordo com a Classificação Internacional de Pneumoconioses ${ }^{6}$, esses casos são rotulados com o código "Normal $0 / 0$ "; esse código apenas permite afirmar que, no momento do exame, não existia ainda a nodulação característica da pneumoconiose; no entanto, como nódulos cujo tamanho é inferior a um milimetro não são radiologicamente verificáveis, a ausência de lesões radiológicas não permite de forma alguma afirmar que tais trabalhadores não apresentem a pneumoconiose. Considerando-se o fato de ser a silicose uma doença caracteristicamente progressiva, é possivel que dentro de algum tempo, que poderá ser de meses a anos, esses trabalhadores venham a apresentar um quadro radiológico característico dessa doença profissional.
Comparando-se os achados radiológicos do presente trabalho com aqueles de Morrone ${ }^{9}$ notam-se diferenças flagrantes e de apreciável interesse. Assim, os trabalhadores de Jundiai, portadores de opacidades arredondadas (formas " $p$ ", " $q$ " $e$ " $r$ ") representavam $94,64 \%$ do total; no caso daqueles observados por Morrone $\theta$ representavam $47,45 \%$ do total, mostrando que os trabalhadores que foram motivo do presente trabalho apresentavam formas mais iniciais da pneumoconiose. Tal fato explica-se porque os casos de Morrone $\theta$ não eram provenientes de um único tipo de indústria, mas sim de numerosas e diversificadas indústrias. Essa discrepância parece permitir que se afirme que nos trabalhadores da indústria cerâmica o processo silicótico progride mais lentamente do que aquele observado em outros tipos de indústria. Essa afirmação, no entanto, tem pouco valor prático pois, sendo a silicose uma doença profissional inexoravelmente progressiva, a constatação de alterações radiológicas mesmo mínimas constitui um fato tão grave como o achado de alterações radiológicas mais pronunciadas; no máximo, tal constatação apenas permitirá afirmar que, salvo em casos de hipersusceptiveis, a doença levará mais tempo para se manifestar clinicamente com os sintomas de insuficiência respiratória progressiva.

Não obstante os resultados da presente pesquisa não terem sido publicados na época (fins de 1975 e início de 1976), por motivos vários, foram eles conhecidos por parte dos dirigentes sindicais de Jundiaí, como já referido. Com isso, criou-se entre os trabalhadores expostos à poeira de sílica na indústria cerâmicá uma preocupação muito grande pelo problema, uma vez que ficou claramente evidenciado que esse tipo de indústria implicava risco de pneumoconiose que até então não fora devidamente avaliado. Assim, sindicatos de trabalhadores de outras áreas do Estado de São Paulo passaram a preocupar-se seriamente com 0 problema, o que levou ao encontro de outro 
NogutiRA, D.P, et al. Ocorrência de silicose entre trabalhadores da indústria cerâmica da cidade de Jindiai, SP (Brasil). Rev. Saüdc pübl., S. Paulo, 15:263-71, 1981.

"foco" de silicose na indústria cerâmica do municipio de Pedreira, bem descrito por Morrone 9 .

Fica, portanto, evidenciado que a partir de um caso de silicose ocorrido na indústria cerâmica, foi possivel epidemiologicamente identificar um "foco" dessa doença profissional que, por sua vez, permitiu identificar outros "focos" no Estado de São Paulo. Verifica-se, pois, a grande importância da metodologia epidemiológica em Saúde Ocupacional, confirmando-se, assim, de forma evidente, o que fora pensado por Collis ${ }^{1}$, há tantos anos atrás.

É importante destacar que desse estudo inicial resultaram alguns benefícios para os trabalhadores expostos a esse risco de doença profissional. Assim, na região de Jundiaí as empresas onde o risco de silicose existe decidiram, em vários casos, modificar seus métodos de trabalho de forma a permitir o trabalho em um ambiente onde os teores de silica livre permanecessem dentro dos limites de tolerância estabelecidos pela legislação brasileira. Por outro lado, os casos ocorridos em Pedreira, em número relativamente elevado, estão merecendo cuidadosa atenção das autoridades e, presentemente, um cuidadoso estudo das condições de trabalho foi realizado por Gana Soto ${ }^{*}$, na FUNDACENTRO que também elaborou projetos que visam eliminar o risco da silicose na atividade ceramista.

Tendo em vista, uma vez mais, o fato de que a silicose é uma doença profissional progressiva, que leva a uma fibrose pulmonar cada vez maior e para a qual nenhum tratamento curativo existe, assume enorme importância epidemiológica a descoberta de uma atividade laborativa onde os trabalhadores estão expostos a risco declarado de adquirir essa tão grave pneumoconiose, indicando de forma clara a necessidade de se adotar o único recurso para evitá-la: a prevenção.

NOGUEIRA, D.P. et al. [Silicosis among workers in the ceramic industry in Jundiai. SP (Brazil) ]. Rev. Saúde públ,, S. Paulo, 15:263-71, 1981.

ABSTRACT: The discovery of one case of silicosis in a ceramic plant-an industry considered a low silicotic risk - led to an X-ray examination of all the workers, which found a high number of cases among them. Radiological findings are described; the majority of which were small, regular opacities in the lungs. It is important to remember that this one case led to the discovery of many more in ceramic plants all over the state.

UNITERMS: Silicosis, Jundiai, SP, Brazil. Occupational diseases. 
NOGUEIRA, D.P. et al. Ocorrência de silicose entre trabalhađores da indústria cerâmica da cidade de Jundial, SP (Brasil). Rev. Saude públ., S. Paulo, 15:263-71, 1981.

\section{REFERENCIAS BIBLIOGRAFICAS}

1. COLLIS, E.L. Industrial pneumoconioses, with special reference to dust-phtisis. Publ. Hlth, 29:11-20: 37-44: 252-64: 292$-305,1915$.

2. DENSEN, P.M. Epidemiology and indistrial health. Industr. Hyg. Dig., 20(11): 37-42, 1956.

3. EVANS, D.J. Cerâmica, indústria. In: Enciclopédia de medicina, higiene y seguridad del trabajo. Madrid, Instituto Nacional de Prevision, 1975. p. 369-73.

4. GANA SOTO, J.M.O. et al. Levantamento do risco potencial de silicose: estudo realizado em indústrias cerâmicas do municipio de Pedreira, São Paulo. Rev. bras. Saúde ocup., 9:71-108, 1981.

5. HUNTER, D. The diseases of occupations. 5 th ed. London. The English Universities Press. 1969.
6. INTERNATIONAL LABOUR OFFICE. International classification of radiographs of pneumoconiosis. Geneva, 1971. (Occupational Safety and Health Series, 22).

7. MENDES, $R$. et al. Introdução geral ao problema das pneumoconioses. In: Mendes, R. Medicina do trabalho: doenças profissionais. São Paulo, Sarvier, 1980. p. $129-96$.

8. MINERVINO, D.M. et al. A silicose pulmonar nas indústrias de São Paulo. In: Congresso Americano de Medicina do Trabalho, São Paulo, 1964. Anais. São Paulo, 1964. p. 268-80.

9. MORRONE, L.C. Epidemiologia da silicose no Estado de São Paulo. São Paulo, 1979. [Dissertação de Mestrado - Faculdade de Saúde Pública da USP]

Recebido para publicação em 07/01/1981 Aprovado para publicação em 11/09/1981 